penicillin. Perhaps it was then that Penicillium notatum was in Florey's coat pocket, or even, from Heatley's account of a practice he suggested earlier, present as spores rubbed on the lapels of their jackets for safekeeping.

The virtue of Lax's approach is that it focuses not only on members of the Oxford team and their relationships with one another but also on the great and the good of Britain and America, who in one way or another helped to make it happen, notwithstanding frequent lapses in their comprehension of the staggering difficulties facing Florey. Lax helps modern readers understand that the 'proof of principle' mouse experiments took place as Dunkirk was being evacuated, and that the consequent push to enhance the supply of penicillin in Oxford coincided with the onset of the Blitz.

Florey's complicated personal life from 1940 onwards is also part of the story. With their children evacuated to the United States from 1941, Ethel and Howard Florey struggled to work out how to remain together while Howard continued his demanding professional life, Ethel found ways to live with deafness and contribute to clinical work with penicillin in Oxford, and - not part of the agreement - Howard turned to his laboratory associate Margaret Jennings for affection, said by one observer to be "one of the worst-kept secrets in Oxford".

There is ample evidence to support Lax's decision to bring Heatley to the foreground, closer to Florey than to Chain. Florey not only valued Heatley's unquestioned experimental skills, gift for improvization and intelligence, he trusted and depended upon him. Heatley's respect for, and commitment to, "the Professor" were unqualified. Lax makes it clear that the chemistry of their relationship enabled Florey to focus on the big issues, channelling his energy and broad intelligence into important pursuits. Thus, when he could leave nothing to chance, Florey turned to Heatley, rather than Chain, for his travelling companion on the Pan American clipper to New York from Lisbon in July 1941, to join him for virtually every meeting in America with industry or government figures, and leaving him behind for a full year to assist and advise the parties who would undertake the large-scale production of penicillin.

Sadly, Heatley never had the opportunity to read Lax's account, as he died on 5 January 2004, just before his 93rd birthday. Had he still been alive, one can imagine him objecting that far too much attention had come his way of late, that luck had always played a large role in the enterprise, and that he agreed with Pasteur: being prepared to recognize good fortune, and having the wits to act upon it, was sufficient.

William Shaw is professor emeritus of biochemistry and chemical microbiology at the University of

Leicester,UK.e-mail:bill.shaw@rcn.com

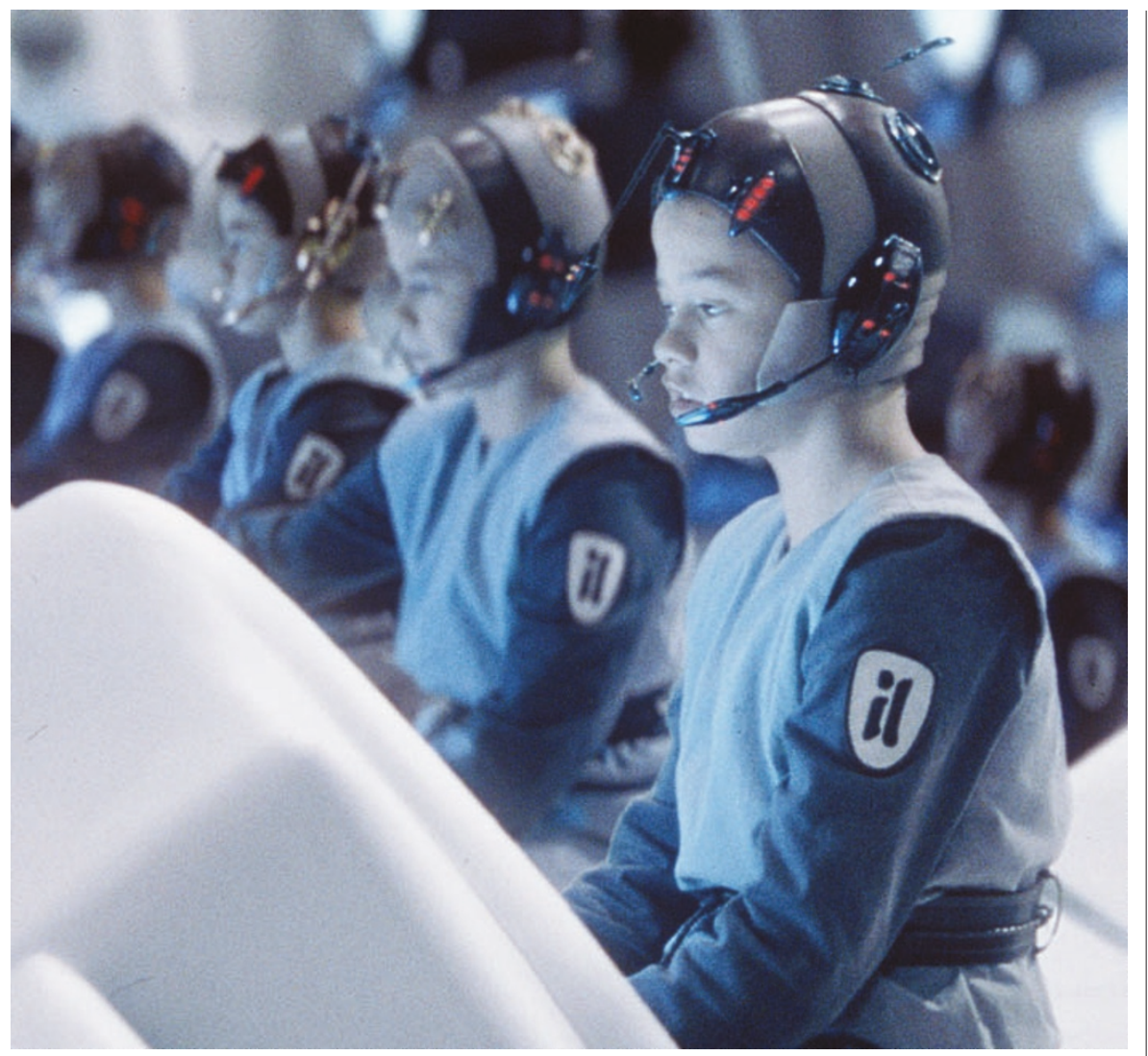

A real risk? Cloning is used to create warriors in Star Wars Episode II: Attack of the Clones.

\section{A clear view of cloning}

\section{A Clone of Your Own? The Science and Ethics of Cloning}

by Arlene Judith Klotzko

Oxford University Press: 2004. 162 pp. $£ 12.99$

\section{John Harris and Tuija Takala}

For members of the general public confused by the heated debate generated by human cloning, A Clone of Your Own? does an admirable job in explaining many of the complicated ethical and scientific issues without giving way to academic jargon. Drawing from literature, the visual arts, films and her personal experiences, Arlene Judith Klotzko has created a comprehensible overview of cloning.

Klotzko tells us about the early experiments that Aristotle did with chicken embryos; about a German scientist, Hans Spemann, who figured out the theory of cloning some sixty years before we actually succeeded in cloning mammals; about Dolly, the first cloned sheep, and other work done at Edinburgh's Roslin Institute; and the current successes and failures in attempts to clone mammals. She explains the basics of embryology and provides an overview of stem-cell research.

The book paints a picture of human cloning as a worthwhile enterprise. Klotzko lists the various potential benefits that therapeutic cloning could have, and explains why we might have reservations about reproductive cloning, even if it should not be banned completely. She also, following several others, clarifies many of the common misconceptions concerning the identity of clones, and puts in plain words the restricted effect that genes have in shaping the kind of people we become.

For a book with radical pretensions, Klotzko's arguments are restrained in their defence of human reproductive cloning she is impressed by the supposed risks entailed. One of the major objections to any current attempt to clone a human is that, in the case of Dolly, only one clone was successfully produced after 277 attempts. Cloning is inefficient and wastes many embryos. But embryo wastage cannot be an objection to reproductive cloning for those who accept natural reproduction - after all, about $80 \%$ of embryos perish in natural reproduction. For every live birth, 3-5 embryos are created only to die.

We must remember that giving birth in the normal way isn't safe for the mother or the child. It is so risky that early abortion is safer for the mother than childbirth. Moreover, $3-5 \%$ of babies born have some abnormality. So the safety of reproductive cloning is at best a contingent argument that fails utterly if cloning could be made safe. Furthermore, the safety argument is interestingly 


\section{Platonic puppetry}

\section{Attila Csörgö's kinetic sculptures bring regular polyhedra to life.}

\section{Martin Kemp}

"Bringing order out of chaos" is a common enough phrase. It is applicable to any act of conspicuous resolution of what was previously a muddle. But in science and art it has more profound resonances. Many scientific experiments and many works of art rely on the setting up of conditions for discerning underlying order, first apparent to the scientist or artist, and then to ourselves as surrogate witnesses. A key difference, historically, is that science has repeatedly used time to set ordering processes in motion, either through the plotting of process or the dynamic achievement of experimental ends. The visual arts, by contrast, have been restricted largely to static evocations of order and disorder.

With the advent during the twentieth century of art that actually moves - sculptures in constant motion or images that exploit the technologies of video and computer graphics - this traditional limitation no longer applies. But it is rare to find motion in art used cyclically to choreograph, first, the transformation of orderly structures into intermediate states in which an inherent order is no longer discernible, and second, the reconstitution of a new regularity which is different from that of the original. Such transformational processes lie at the heart of the spectacularly intricate sculptures by Hungarian artist Attila Csörgö.

The dimension of time is embedded in all his work, whether it involves the rotational imprinting of an all-round image on a hemisphere by a spiralling camera, or devices in which apparently inchoate elements assume legibility under rotational motion. His most famous works, which first attracted international renown at the Hungarian pavilion in the Venice Biennale in 1999, exploit extraordinary mechanical contraptions to dismember and reconstruct the platonic solids - the five regular polyhedra that Plato believed to be
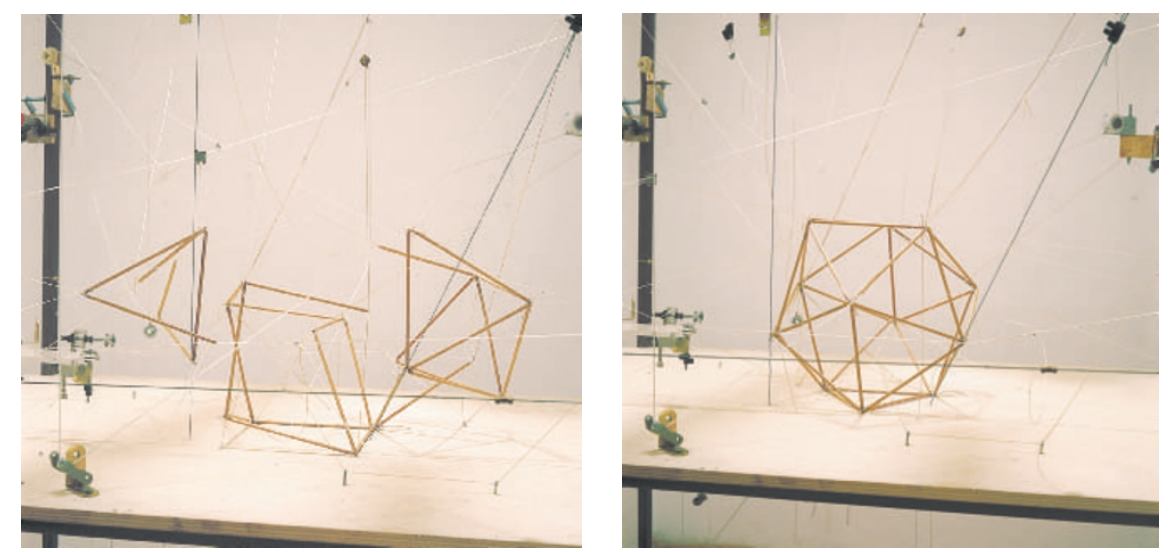

Taking shape: Attila Csörgö’s geometrical figures are constructed and taken apart in real time.

the shapes of the fundamental components of the physical universe.

In the middle of a racked apparatus of electric motors, strings, pulleys and weights sit the skeletal shapes of a tetrahedron, an octahedron and a cube, composed, respectively, of 6, 12 and 12 wooden batons. As the apparatus whirs into motion, the cat's cradle of strings pulls the rods apart, deconstructing the geometrical figures. The rods wheel into space like the disarticulated limbs of broken puppets. If we could trace the tracks of the ends of the rods, we could mentally wind back time to realize the order still distantly immanent in the array. What happens next is not an exact reconstitution, however. The components twist unerringly to settle, end on end, into one of the more complex solids - a dodecahedron in one of the apparatuses, and an icosahedron in another. Momentarily resolved, the mechanisms then embark on the reverse direction of the cycle of dissolution and crystallization.

The process is beguiling, like a musical composition reaching a resolution that seems inevitable yet remains surprising. The visual quality even has a sensual dimension - a quality suggested by the title of Csörgö's new exhibition, 'Platonic Love', which is at Kettle's Yard, University of Cambridge, until 9 May. He is tapping into the enduring aesthetic of the geometrical bodies, which has long fired cosmologists of a keplerian bent.

The geometrical results could, of course, have been achieved through computer graphics, but the visibility and evident physicality of the mechanisms are integral to the spectator's engagement. Our fascination with the raw mechanics of the process is akin to our continued delight in simple optical illusions, even in an age overloaded with film, TV, video and computer animations.

Csörgö, like a scientist, presents us with an anatomized vision of what lies inside dynamic phenomena, of how an array of no discernible order can be coherently characterized within a temporal frame as a moment in a constant flux between two oscillating states of resolution.

Martin Kemp is professor of the history of art at the University of Oxford,Oxford OX1 1PT, UK, and co-director of Wallace Kemp Artakt.

www.kettlesyard.co.uk/exhibitions/csorgo two-edged. If any reproductive technology, including cloning, could be made safer than normal sexual reproduction (as may well eventually happen), then those who regard safety as decisive would have to abjure sexual reproduction for its safer technologybased counterpart.

The great promise of cloning in terms of human welfare, however, lies in the use of these techniques not for reproduction but for therapeutic purposes. The regenerative properties of stem cells that make them so attractive as a possible therapeutic tool also mean that the distinction between therapy and enhancement will inevitably be further eroded. Treatments that cause tissue to repair itself in situ and go on doing so are likely to extend lifespan. If therapies are developed that modify cells to be resistant to cancer or HIV/AIDS, this will create unprecedentedly enhanced humans. Anyone who is disturbed by such a prospect will have the most agonizing of choices to make if the promise of stem-cell research is fulfilled.

A Clone of Your Own? provides engaging and clear explanations of both the basic scientific issues and related ethical issues surrounding cloning. Klotzko appears to have drawn on a wide range of published work on the ethics of cloning, and makes a large proportion of the arguments in the literature accessible in this short book. However, readers who are unaware of the literature may be left with the impression that Klotzko is the first, and almost the only, person to have written on the ethics of cloning, which is far from the case. It is a pity that the author and the publisher have provided so little reference to the extensive ethics literature and given so little sign that they are even aware of it. Whether one's interest lies in the science or the ethics of cloning, the short list of further reading provided at the end of the book is unhelpful and misleading.

But this caveat aside, the drawings and other illustrations, and Klotzko's narration, make the book highly approachable. Members of the public who would like to understand what the debate on human cloning is all about should read this book.

John Harris and Tuija Takala are at the Institute of Medicine, Law and Bioethics, University of

Manchester, Manchester M13 9PL, UK. 